\title{
25. DISSOLVED GASES IN BLACK SEA SEDIMENTS
}

\author{
John M. Hunt and Jean K. Whelan, Woods Hole Oceanographic Institution, Woods Hole, Massachusetts
}

Most Black Sea cores contained dissolved gases which expanded as the cores were brought to the surface. This caused the core sections to be separated at various points. Some cores contained sufficient gas to blow the core out the end of the barrel upon removal of the core catcher. The gases, which were sampled and analyzed on shipboard, were mostly methane with small amounts of carbon dioxide and other hydrocarbon gases. The equipment on the ship was not sensitive enough to analyze the higher hydrocarbon gases in detail so this was done at Woods Hole Oceanographic Institution.

About 300 gas samples were analyzed from Holes $379,380 / 380 \mathrm{~A}$, and 381 . Data for the higher hydrocarbons, ethane through the pentanes are shown in Figures 1, 2, and 3 . The ethane concentration ranges from 1 to about 1000 parts per million ( $\mathrm{ppm}$ ) by volume of the total gas. Propane varied from 1 to $100 \mathrm{ppm}$, butanes from about 0.1 to $100 \mathrm{ppm}$, and pentane from 0.1 to $20 \mathrm{ppm}$. At all three sites the concentrations of the higher hydrocarbons increased irregularly with depth. In Hole $379 \mathrm{~A}$ ethane increased steadily to a depth of about 450 meters after which there was a slight decrease. The higher hydrocarbons increased to a depth of about 300 meters after which their yields dropped sharply and then increased slightly to about 450 meters followed by a leveling off.

In Holes $380 / 380 \mathrm{~A}$ all of the higher hydrocarbons increased irregularly to a depth of about 350 meters with the ethane showing the most rapid increase. At this point there is a slight decrease in the propane, butanes, and pentanes after which these hydrocarbons begin increasing at a faster rate than the ethane. At a depth of about 900 meters there is a decrease in all of the higher hydrocarbons. The decrease at 350 meters correlates with the appearance of sideritic muds and that around 900 meters with the appearance of dolomites. Thus, the changes seem to correlate with lithology, but all of the hydrocarbons do not change at the same rate.

In Hole 381 there is a general increase in higher hydrocarbons with depth down to 350 meters where a sharp drop occurs. There is a sampling gap from here to about 450 meters, but it appears that the deeper samples simply represent a continuation of the same rate of increase as near the surface. The sudden drop in yields at about 350 meters appears to correlate with the appearance of breccia. This may be a migration phenomenon since breccia would be more likely to contain methane which has migrated in from surrounding fine-grained source sediments. Migration of the methane would result in a lower concentration of the higher hydrocarbons since the methane migrates more rapidly.
The butanes and pentanes curves in Figures 1, 2, and 3 represent the sum of the isomers. Since the branched and straight chain hydrocarbons may have different sources, it was of interest to compare the ratios of the hydrocarbon isomers. Figure 4 contains plots of the isobutane/n-butane and isopentane plus neopentane $/ n$-pentane ratios with depth. The neopentane effect is significant mainly in Hole 381 where its concentration sometimes exceeded that of isopentane.

The isobutane $/ n$-butane ratio showed no change with depth in all three holes. Data for Holes 379 and 381 are shown in Figures 4 and 5. The results from Hole 380 were similar. However, the ratio of branched to normal pentanes increased irregularly with depth in all three holes. The rate of increase was fastest in Hole 381 and slowest in 380 , but it was very similar in all three. The increase is due to the fact that the isopentane is increasing while the $n$-pentane is constant with depth as shown in Figure 6. Also, in Hole 381 there is an increase in neopentane with depth with the largest jump in yield occurring at 110 meters. The neopentane is believed to be forming from the decomposition of gem dimethylcycloalkanes which are derived from the terpenes of terrestrial organic matter. The fact that neopentane is found in large amounts in Hole 381 but not in $380 / 380 \mathrm{~A}$ indicates that some types of organic detritus are not carried very far from the land surface. Hole 381 is presumed to be the closest to shore of the three sites during this period of deposition. The change in the ratio of isopentane to $n$-pentane with depth in the three Black Sea holes is shown in Figure 7 compared to the same change in Cretaceous age Paris Basin shales and calculated equilibrium values. The change in this ratio with depth is in the opposite direction than would be expected from purely thermodynamic considerations. The more stable isomer is $n$-pentane and calculated equilibrium values show that with increasing temperature there will be a steady decrease in this ratio. The results in Figure 7 indicate that more isopentane is available from early biological and diagenetic reactions of organic matter than is $n$-pentane. This would be expected since isopentenyl pyrophosphate is the biosynthetic pathway leading to isoprenoid hydrocarbons. The branched isopentane structure should be very common in an immature organic matrix.

The hydrocarbon gas data shown in these figures clearly indicate that these gases are forming in situ and are not the result of diffusion of gases from great depth. Also, carbon-13 data were obtained on 10 of the gases indicating that the methane is biological in origin. These data are shown in Table 1 . The $\delta \mathrm{C}^{13}$ PDB values for 10 samples from Holes 379,380 and 381 range from -63 to $-72 \%$. Methane formed biologically generally ranges from -55 to -80 while the methane in petroleum 


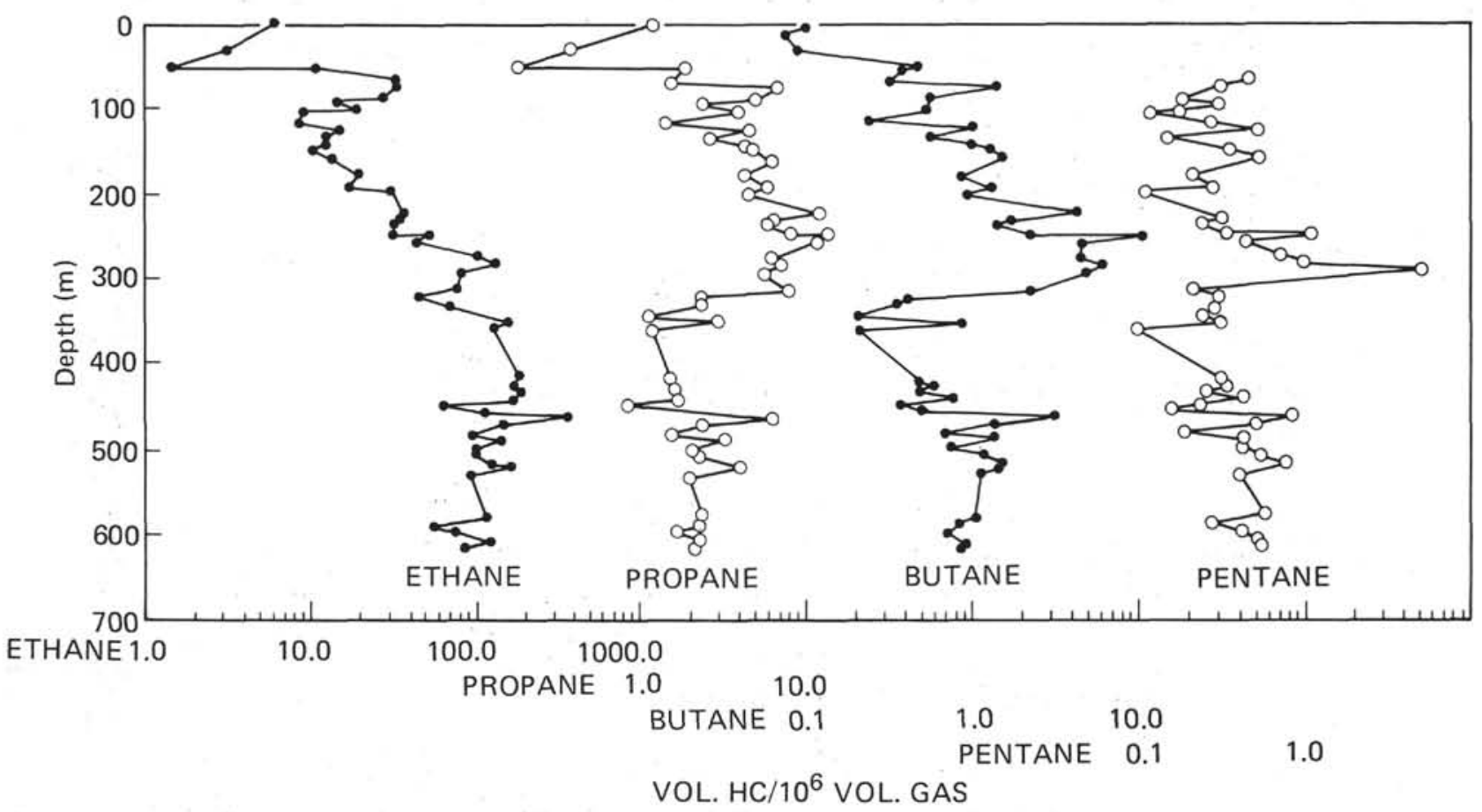

Figure 1. Core pocket gas, Hole 379A. PPM by volume of $C_{2}$ to $C_{5}$ hydrocarbons.

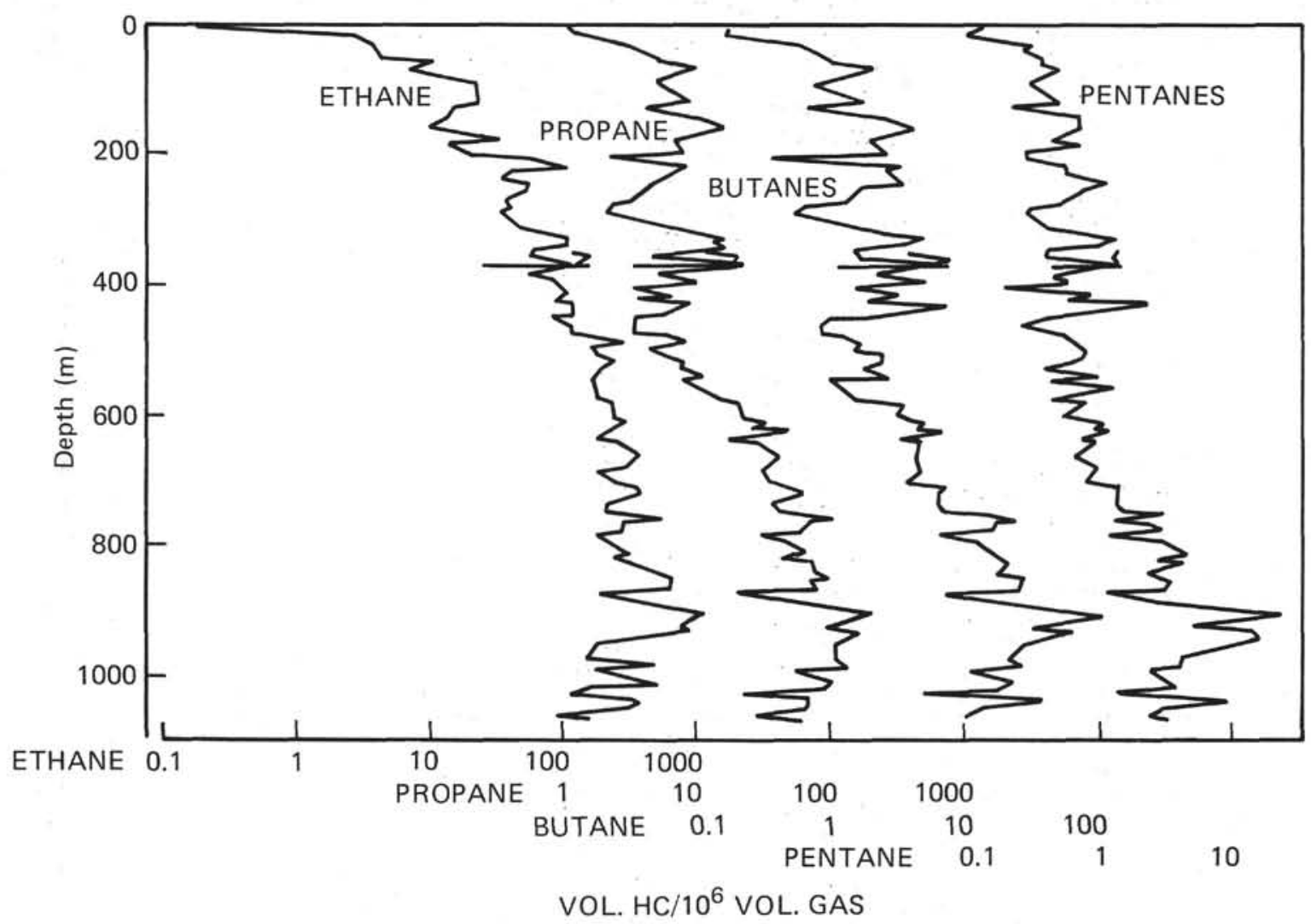

Figure 2. Core pocket gas, Hole 380/380A. PPM by volume of $C_{2}$ to $C_{5}$ hydrocarbons. 


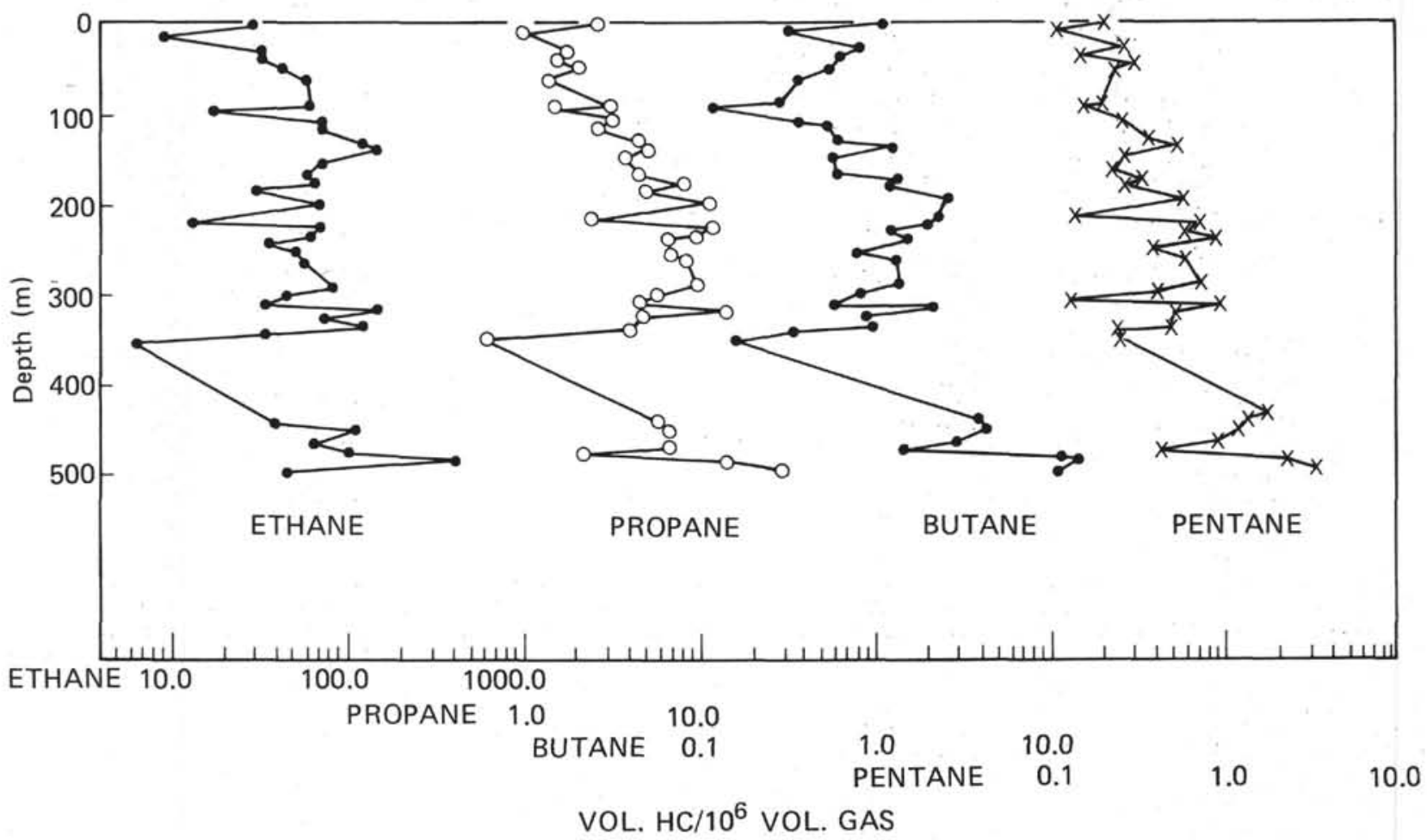

Figure 3. Core pocket gas, Site 381. PPM by volume of $C_{2}$ to $C_{5}$ hydrocarbons.

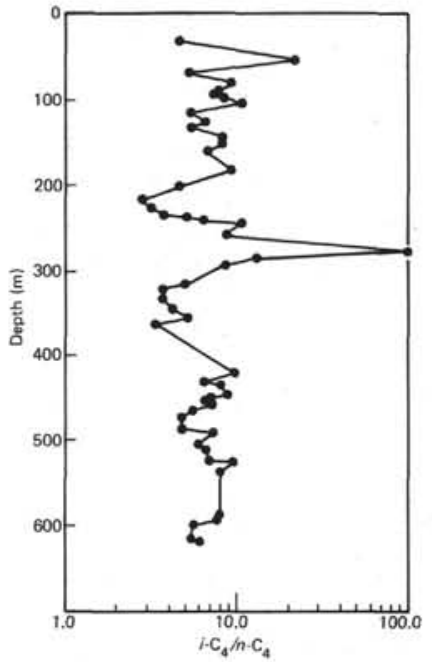

Figure 4. Core pocket gas, Hole 379A. Ratios of isobutane $\mathrm{n}$-butane and branched $C_{5} / n$-pentane where branched $C_{5}$ equals i-pentane plus neopentane.

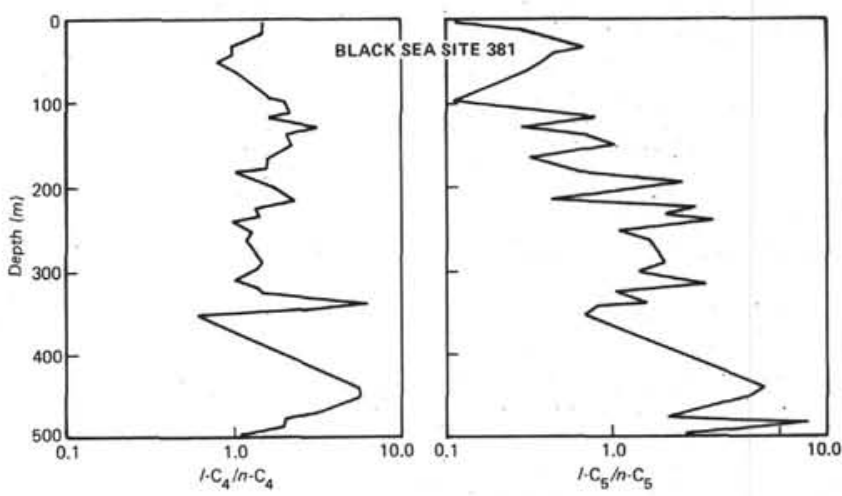

Figure 5. Core pocket gas, Site 381. Ratios of isobutane nbutane and isopentane/n-pentane. 


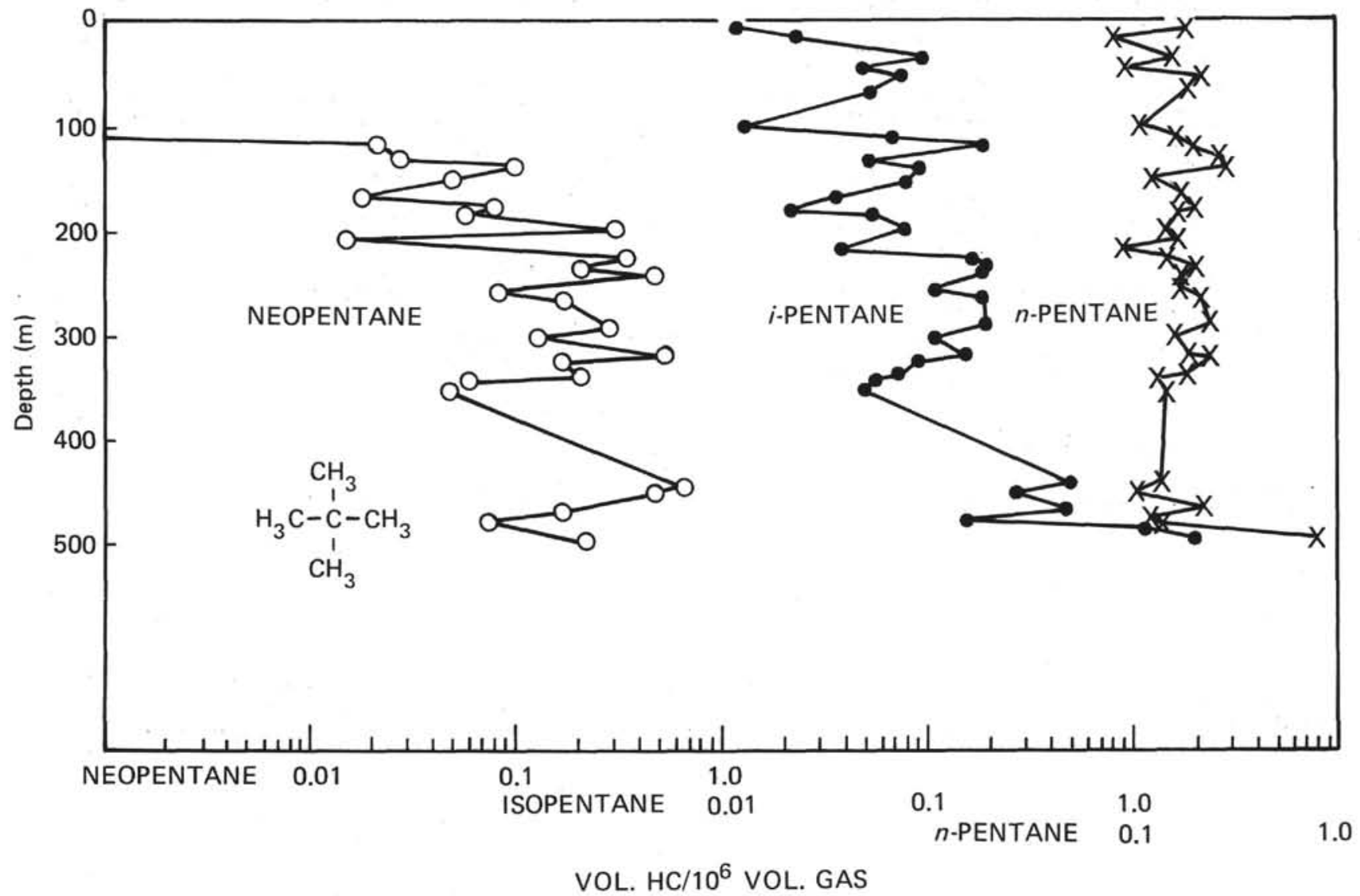

Figure 6. Core pocket gas, Site 381. PPM by volume of $C_{5}$ isomers. 


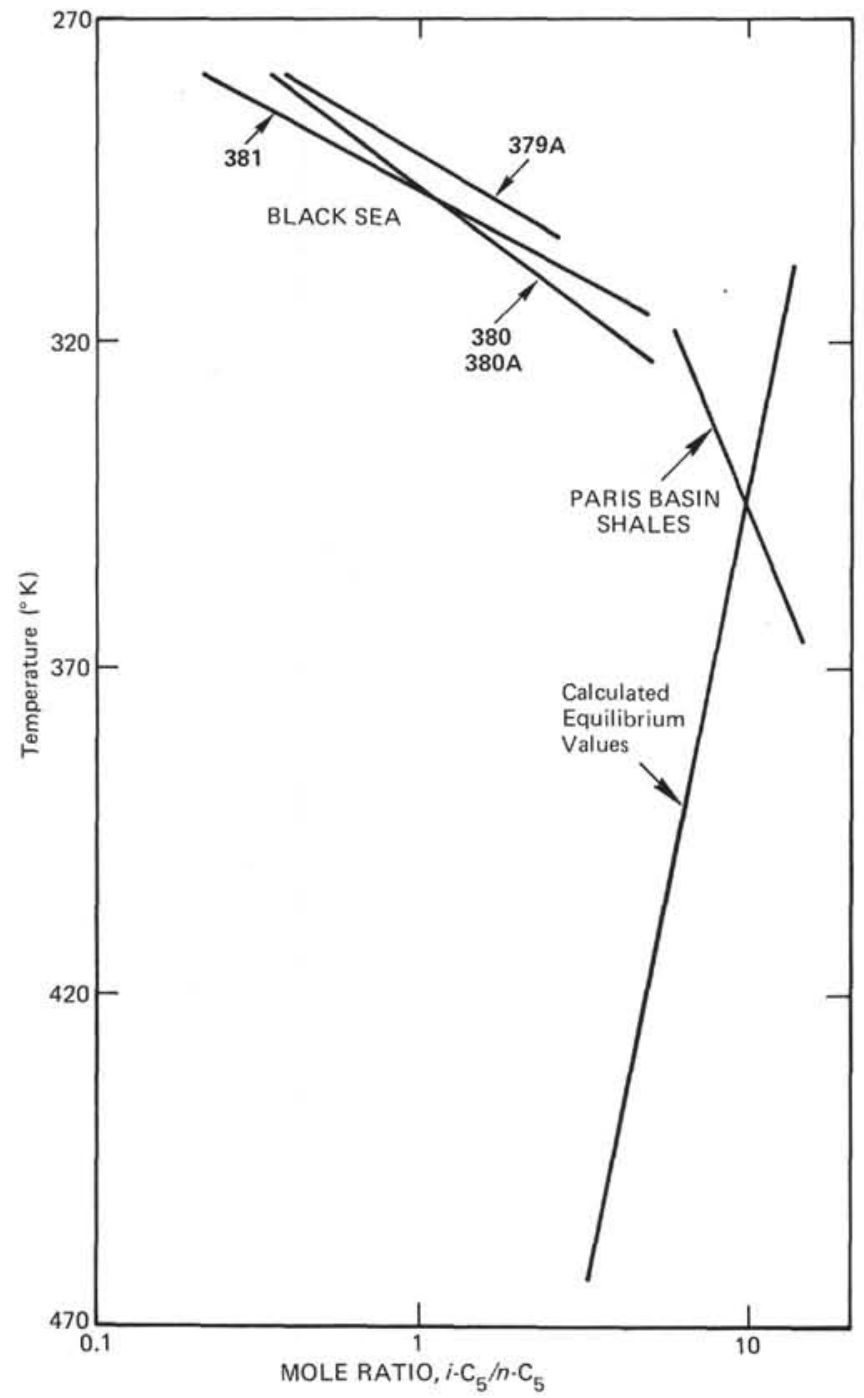

Figure 7. Comparison of observed and calculated $i-C_{5} / n-C_{5}$ ratios.
TABLE 1

Carbon-13 Data on Methane From Black Sea Cores

\begin{tabular}{lrl}
\hline $\begin{array}{c}\text { Sample } \\
\text { (Interval in cm) }\end{array}$ & Depth $(\mathrm{m})$ & $\delta \mathrm{C}^{13}{ }_{\mathrm{PDB}}^{\% \mathrm{a}}$ \\
\hline $379 \mathrm{~A}-4-5,54$ & 33 & -66 \\
$379 \mathrm{~A}-45-4,100$ & 412 & -66 \\
$379 \mathrm{~A}-67-2,77$ & 608 & -65 \\
$380 \mathrm{~A}-1-6,115$ & 9 & -70 \\
$380 \mathrm{~A}-8-5,116$ & 406 & -65 \\
$380 \mathrm{~A}-46-4,76$ & 756 & -63 \\
$380 \mathrm{~A}-79-2,0$ & 1066 & -65 \\
$381-6-4,31$ & 52 & -72 \\
$381-17-6,63$ & 151 & -63 \\
$381-51-3,50$ & 469 & -67 \\
\hline
\end{tabular}

${ }^{a}$ Analyzed by W. Deuser and E. Ross, WHOI.

reservoirs ranges between about -25 and -50 . The data in Table 1 clearly indicate a biological source for the methane.

The higher hydrocarbons were present in such small amounts that a carbon isotope analysis was not possible. However, it is probable that they are originating from a combination of initial biological breakdown of the organic matter plus low temperature diagenetic chemical reactions. Propane and butanes have previously been detected in Black Sea water so it is not unexpected to find them in the sediments.

\section{ACKNOWLEDGMENT}

This work was supported by a National Science Foundation Grant OCE73-06575. 